\title{
Plant-mediated biosynthesis of silver nanoparticles by leaf extracts of Lasienthra africanum and a study of the influence of kinetic parameters
}

\author{
ELIAS E ELEMIKE ${ }^{1,2,3}$, DAMIAN C ONWUDIWE ${ }^{1,2, *}$, OLAYINKA ARIJEH ${ }^{3}$ \\ and HENRY U NWANKWO ${ }^{1,2}$ \\ ${ }^{1}$ Material Science Innovation and Modelling (MaSIM) Research Focus Area, Faculty of Agriculture, Science and \\ Technology, North-West University, Mafikeng Campus, Private Bag X2046, Mmabatho 2735, South Africa \\ ${ }^{2}$ Department of Chemistry, School of Mathematics and Physical Sciences, Faculty of Agriculture, Science and \\ Technology, North-West University, Mafikeng Campus, Private Bag X2046, Mmabatho 2735, South Africa \\ ${ }^{3}$ Department of Chemistry, College of Science, Federal University of Petroleum Resources, PMB 1221, Effurun, Nigeria
}

MS received 6 May 2016; accepted 24 June 2016

\begin{abstract}
Lasienthra africanum (LA) leaf extract was employed for nano-silver synthesis. The reducing effect of the plant extract was investigated at different times, $\mathrm{pH}$, temperatures and concentrations. The effect of various kinetic parameters was studied using UV-vis spectroscopy. Blue-shifted surface plasmon bands indicating smaller sized nanoparticles were obtained at neutral pH (6.8-7.0), temperature of $65^{\circ} \mathrm{C}$ and concentration ratio of $1: 10$ (leaf extract: $\mathrm{AgNO}_{3}$ ) with increasing reaction times under the reaction conditions. The kinetics of the reaction followed pseudo-first- and -second-order rate equations, and was thermodynamically favoured at higher time. Spherically shaped nanoparticles were obtained at different reaction conditions.
\end{abstract}

Keywords. Silver nanoparticles; thermodynamics; kinetics; biosynthesis; plasmon bands.

\section{Introduction}

In recent years, the synthesis of nanoparticles using easily available biological materials has created a new field in nanobiotechnology. This approach has provided new avenues for the synthesis of nanoparticles and is an eco-friendly, simple, rapid, stable and cost-effective method [1,2]. With different biomaterials, new and exciting material characteristics emerge, thereby giving room for various bio-nanosynthesis and opening up new innovations. The behaviour of nanoparticles in solution often dictates important functional properties such as size- and shape-dependent plasmonic response, magnetic response, biomolecular detection, biosensors, medical diagnostics and catalytic activity [3]. The size of silver nanoparticles (AgNPs) is very important in many of these applications; hence the controlled synthesis is one of the most challenging tasks for the development of novel nanotechnology [4]. The size effect in the AgNPs can be evidenced from the blue-shifts of optical absorption spectrum, making it an attractive inorganic material for study [5].

Lasienthera africanum (LA), which contains the reducing component in this research, is found mainly in the humid tropical forest regions of Central African Republic, Cameroon, Gabon, Democratic Republic of the Congo and Angola [6]. The plant LA belongs to the order Celestrales, which comprises 13 families of trees and shrubs with simple leaves, and belongs to the family Icacinacea [7]. It contains

*Author for correspondence (Damian.Onwudiwe@nwu.ac.za) bioactive agents such as alkaloids, saponins, flavonoids, tannins, anthraquinones, plobatannins, cyanogenetic glycosides and cardiac glycosides. These groups of plants and shrubs are of importance both nutritionally and medicinally, and can be called nutraceuticals [8]. L. africana is one such plant as its stem is used to clean the teeth and the water extract of the leaf is reported to control stomach ulcer $[9,10]$. Udosen et al [11] reported that the leaves of $L$. africana of both young and old plants are rich in minerals such as $\mathrm{Ca}, \mathrm{P}, \mathrm{Mg}, \mathrm{Fe}$ and $\mathrm{Zn}$ as well as antinutrients - total soluble oxalates and HCN. However, the young leaves contain significantly higher values of crude fat, crude protein, $\mathrm{P}$ and $\mathrm{Zn}$ than the old leaves.

In the synthesis of nanoparticles via green approach, biological entities such as plant materials, microorganisms and living cells are the best examples of machines that possess operating parts at the nanoscale level. A number of activities ranging from generation of energy to extraction of targeted materials at a very high efficiency are being carried out within these entities [12]. Biotechnological approach towards the synthesis of nanoparticles has many advantages such as ease with which the process can be scaled up, economic viability, possibility of easily covering large surface areas exhibited by the substrates and its green chemistry nature provided the medium is a suave one [13].

In plant-mediated synthesis, the control of the size of AgNPs is found to be time dependent. Basically, the longer the reaction time, the larger the size and the nanoparticles also change from polycrystalline to single crystalline [14]. These time-dependent features in the UV-vis spectra are characteristics of aggregated spherical nanoparticles 
or anisotropic nanostructure whose dimension changes with time [15]. Other important physical parameters in the synthesis of AgNPs are temperature and $\mathrm{pH}$ [16-18]. Chandra et al [17] reported an increase in absorbance with temperature of nanoparticles synthesized using Aloe-vera extract. The experiment suggests that the low rate of $\mathrm{Ag}$ nanoparticles at room temperature can be made larger by increasing the temperature of the reaction mixture. Increase in the reaction temperature led to a rapid reduction rate of the $\mathrm{Ag}^{+}$ions and subsequent homogeneous nucleation of silver nuclei, giving rise to the formation of Ag nanoparticles with small size. The $\mathrm{pH}$ of the reaction medium plays a role in the nanoparticle synthesis by inducing the reactivity of leaf extract with silver ions. Pandey et al [18] reported the appearance of small but broad surface plasmon resonance (SPR) bands at low $\mathrm{pH}$, which indicated the formation of large size nanoparticles. In the synthesis of nanoparticles mediated by Coleus aromaticus leaf extract, the maximum production of nanoparticles depicted by a sharp peak was observed at $460 \mathrm{~nm}$ in alkaline $\mathrm{pH}$ of 8.2 [19]. The sharp peak also indicates formation of disaggregated, isotropic and uniform size AgNPs [20,21].

The UV-vis spectroscopy has been used to obtain information on the effect of these kinetic parameters, including the effect of silver nitrate concentration on the AgNPs synthesis. In a report by Vanaja et al [22], silver nitrate of different concentrations ranging from 1 to $5 \mathrm{mM}$ was used as the precursor to prepare AgNPs. Narrow bands were observed with increased absorbance at $1 \mathrm{mM}$, whereas other concentrations showed a broad peak at $460 \mathrm{~nm}$. The absorption increased with increase in the concentration of silver ions. At $1 \mathrm{mM}$ concentration, the nanoparticles synthesis and size reduction occurred quickly due to the availability of functional groups in the leaf extract. Increasing the substrate concentration leads to larger size and aggregation of nanoparticles due to competition between the silver ion and the functional groups of the leaf extract, while increase in intensity of the plasmon band given by the UV-vis analysis shows higher concentration of the nanoparticles. In this work, LA-leaf-extract-mediated synthesis of AgNPs is reported, and the effect of the variation of kinetic parameters on the biosynthesized AgNPs is investigated using UV-vis spectroscopy.

\section{Materials and methods}

\subsection{Preparation of leaf extract}

LA, locally known as 'Editan' leaves, was bought from the local market in Warri, Delta state, Nigeria. The fresh leaves were rinsed thoroughly with tap water followed by distilled water to remove dirt, then chopped into pieces, dried at room temperature and ground into fine powder. About 10 $\mathrm{g}$ of these finely ground leaves was weighed into a $250 \mathrm{ml}$ beaker containing $100 \mathrm{ml}$ distilled water and boiled for about $20 \mathrm{~min}$. It was then filtered and the filtrate used for AgNP synthesis.

\subsection{Biosynthesis of AgNPs}

In a typical biosynthesis of AgNPs, $10 \mathrm{ml}$ of the filtrate from the plant extract was added to $50 \mathrm{ml}$ of $1 \mathrm{mM} \mathrm{AgNO}$. The resulting solution was heated at different temperatures (35, 45,55 and $65^{\circ} \mathrm{C}$ ) in a water bath. Aliquot samples of the mixtures were taken at intervals $(0,15,30,45$ and $60 \mathrm{~min})$ and also at different $\mathrm{pH}(4,7$ and 10). The formation of surface plasmon bands and the rate of reduction of $\mathrm{Ag}^{+}$ions to $\mathrm{Ag}^{0}$ shown by the colour change of the mixture from light yellow to yellowish brown and finally to reddish brown was monitored periodically using a UV-vis spectrophotometer.

\subsection{Characterization of AgNPs}

2.3a The UV-vis spectroscopy measurements: The reduction of silver ions was routinely monitored by visual inspection of the solution as well as by measuring the UV-vis spectra of the solution by periodic sampling of aliquots $(1.5 \mathrm{ml})$ of the aqueous component. The UV-vis spectroscopy measurements were recorded on an M560 UV-vis spectrophotometer operated at a resolution of $1 \mathrm{~nm}$.

2.3b Variation of kinetic parameters: The synthesis was carried out at different temperatures $\left(35,45,55\right.$ and $\left.65^{\circ} \mathrm{C}\right)$, $\mathrm{pH}(4,7$ and 10$)$ and different reaction time (0-60 min) intervals. The effect of the ratio of volume of LA leaf extract to that of $1 \mathrm{mM} \mathrm{AgNO}_{3}$ was also studied. Pseudo-first-order and -second-order kinetic equations were used to model the rates of the nanoparticle synthesis using the maximum absorbance values at a particular wavelength.

$$
\ln A_{0}-A=K_{1} T \text {. }
$$

The first order graph was obtained by plotting $\ln A$ against $T$, whereby the slope is $-K$.

$$
1 / A-1 / A_{0}=K_{2} T \text {. }
$$

The second order graph was obtained by plotting $1 / A$ against $T$, whereby the slope is $K$.

2.3c Transmission electron microscopy analysis: The TEM analysis of the nanoparticles was carried out using a JEOL-3010 field emission electron microscope with accelerating voltage of $50 \mathrm{kV}$. The samples for TEM analysis were prepared from the aqueous solution of the AgNPs sonicated for about an hour. The solution was dropped on a carboncoated copper grid and dried at ambient condition before analysis.

\section{Results and discussion}

\subsection{UV-vis spectroscopy studies}

This spectrophotometric analysis records the intensity of absorption $(A)$ or optical density (OD) as a function of 
wavelength. Absorbance is directly proportional to the path length, $L$, and the concentration, $C$, of the absorbing species according to Beer-Lambert Law. The UV-vis spectroscopy can be used to examine the concentration, size and shapes of the nanoparticles in aqueous suspensions and it serves as the most convenient technique for the characterization of AgNPs $[23,24]$.

Colloidal solutions of AgNPs show bright colours, which is attributed to collective oscillation of free conduction electrons induced by an electromagnetic field. The synthesized AgNPs were reddish brown in aqueous solution due to excitation of electrons and changes in electronic energy levels, reflecting the reduction of $\mathrm{Ag}^{+}$into $\mathrm{Ag}^{0}$ [25]. Morphology of the nanoparticles is greatly influenced by the SPR, since it is the basis for measuring adsorption of materials unto the surface of the metal nanoparticles [26,27]. At a temperature of $35^{\circ} \mathrm{C}$, the formation of the nanoparticles was observed with a characteristic plasmon band at $413 \mathrm{~nm}$, which appeared at 30 min reaction time (figure 1a). The intensity of the peaks continued to increase from time $t=30 \mathrm{~min}$ up to $t=45 \mathrm{~min}$ with slight variation in the absorption maxima. As the reaction continued beyond $45 \mathrm{~min}$, a decrease in intensity of the peak and an increase in size of the nanoparticles occurred at $t=60 \mathrm{~min}$ (figure 1a). The overlapping of plasmon bands at $t=30$ and $t=45 \mathrm{~min}$ implies the formation of stable nanoparticles at $45 \mathrm{~min}$ growth time, and this indicates that the reaction should be terminated if nanoparticles of small size are desired. These oscillations, which appeared as plasmons, depend on the particle size. A shift in the plasmon absorption maximum to longer wavelength, accompanied with bandwidth increase, is observed with increase in size of the nanoparticles [27].

\subsection{Temperature effect on surface plasmon bands (SPBS)}

At temperature of $35^{\circ} \mathrm{C}$, using 1:5 ratio of the extract to the precursor (figure 1a), noticeable SPBs appeared at $422 \mathrm{~nm}$ at $30 \mathrm{~min}$ reaction time and was stabilized up to $t=45 \mathrm{~min}$ as shown by the overlapping of the SPBs. At $t=60 \mathrm{~min}$, a decrease in intensity and red-shift was observed, which indicates a reduction in the concentration of nanoparticles and predominant size increase. In figure $1 \mathrm{~b}$, at $45^{\circ} \mathrm{C}$, SPBs of higher intensity are observed at $15 \mathrm{~min}$, which increase up to $30 \mathrm{~min}$. However, a drastic reduction occurred at $t=$ 45 min with a subsequent slight increase at $t=60 \mathrm{~min}$. This behaviour could be ascribed to the consequence of the instability of the nanoparticles, which may result due to the desorption of the biomolecules, thereby reducing the concentration of the AgNPs formed, as evidenced by the lower intensity recorded at $60 \mathrm{~min}$. However, an optimum duration is required, as AgNP agglomeration after the optimum duration results in larger particle sizes [28]. In other words,
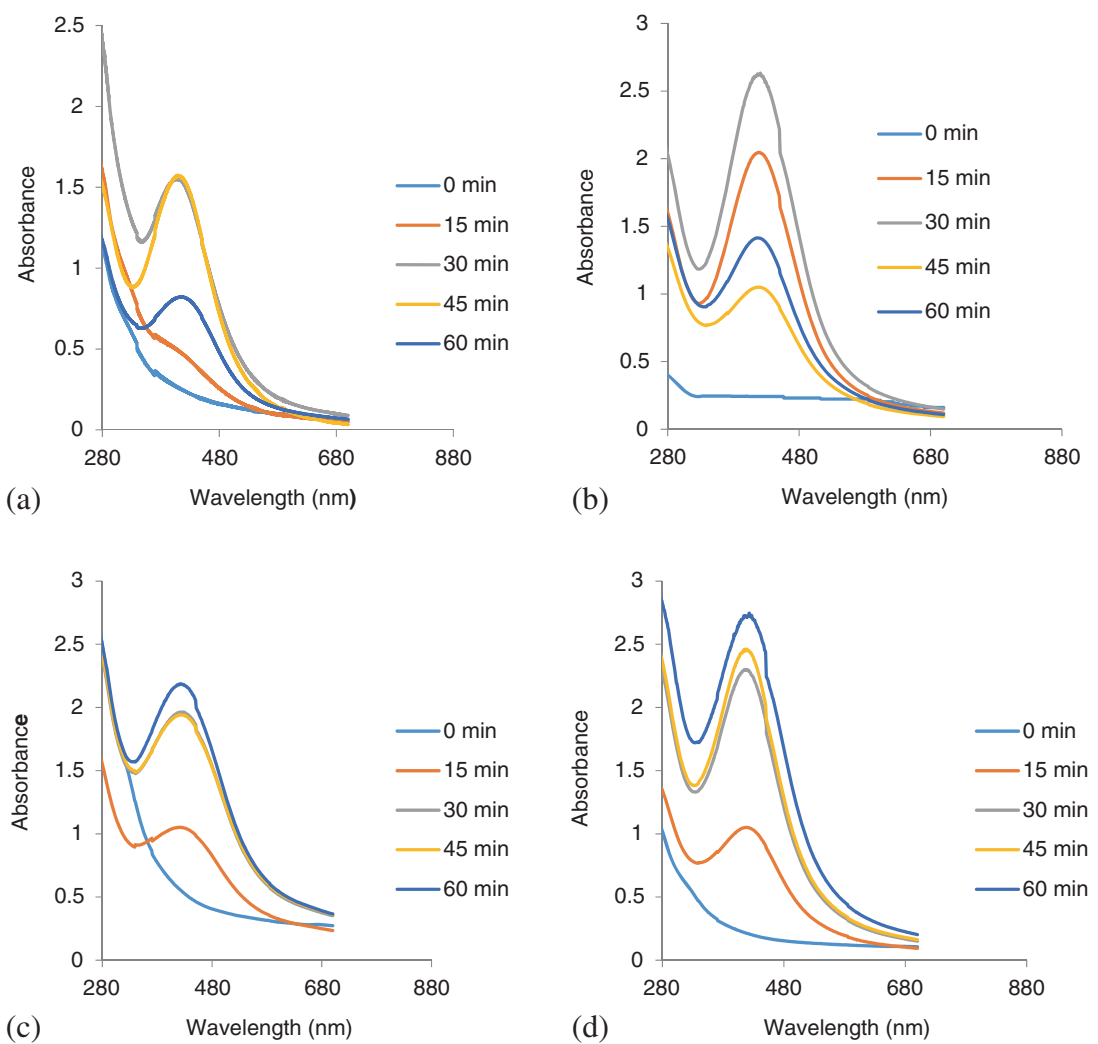

Figure 1. UV-vis absorption spectra of LA-mediated silver nanoparticles measured at (1:5) ratio of extract to $\mathrm{AgNO}_{3}$ at (a) 35, (b) 45, (c) 55 and (d) $65^{\circ} \mathrm{C}$ reaction temperature. 
there could be aggregation, which leads to reduction in total number of nanoparticles over the growth time. This observation is in accordance with earlier reports by other studies, and gives rise to aggregation, coalescence and Ostwald ripening (OR) $[29,30]$.

As the temperature increases from 55 to $65^{\circ} \mathrm{C}$, as shown in figures $1 \mathrm{c}$ and $\mathrm{d}$, there seems to be a more stabilizing effect indicated by gradual increase in the intensity of the nanoparticles with increase in reaction time. Moreover, there was an observed blue-shift from $441 \mathrm{~nm}(15 \mathrm{~min})$ to $432 \mathrm{~nm}$ (60 min) at temperature of $55^{\circ} \mathrm{C}$; and from $444 \mathrm{~nm}(15 \mathrm{~min})$ to $431 \mathrm{~nm}(60 \mathrm{~min})$ at $65^{\circ} \mathrm{C}$ followed by narrowing of the peaks, which suggests particle size reduction [19].

\subsection{Effect of concentration}

Different ratios of the LA extract to the metal ion also resulted in the wavelength shift of the plasmon bands. However, the initial metal ion concentration and the reaction time also played crucial roles in the optical properties and the size of the nanoparticles obtained. The reduction of the substrate to precursor concentration from 1:5 to 1:10 resulted in increase in absorbance with remarkable blue-shifts in the plasmon bands formed, especially at $65^{\circ} \mathrm{C}$, as shown in figure $2 \mathrm{~d}$. In earlier reports in which gold and silver nanoparticles were produced using extracts of Eucalyptus macrocarpa [31], A. vera and Camellia sinensis [32], the optical properties of the nanoparticles were also found to be dependent on the initial concentration of the metal salts and the extract. The size and shape of the nanoparticles could be controlled by changing the concentration of the extract [33].

\subsection{Effect of $\mathrm{pH}$}

The $\mathrm{pH}$ values play an important role in the formation of small size nanoparticles as shown in figure 3a-d. At LA extract to $\mathrm{AgNO}_{3}$ ratio of 1:5, the $\mathrm{pH}$ of 4 resulted in lower intensity after reaction time of $45 \mathrm{~min}$ and the intensity increased with blue-shift from 430 to $427 \mathrm{~nm}$ after $60 \mathrm{~min}$, as shown in figure $3 a$ and $b$. The effect of $\mathrm{pH}$ on the size and amount of AgNPs synthesized in this ratio is complicated. In figure $3 \mathrm{c}$ and $\mathrm{d}$, with volume ratio of $1: 10$, there is a clear indication that the reaction is favoured in neutral medium with formation of narrower peaks that tend towards lower wavelengths. Moreover, the intensities of the SPBs were stronger. Huang et al [34] reported that $\mathrm{pH} 12.4$ is an ideal condition for the preparation of AgNPs using carboxy methyl chitosan as a stabilizing agent, while Ramnani et al [35] reported that neutral and acidic media are desired for synthesis of $\mathrm{Ag}$ clusters on $\mathrm{SiO}_{2}$. Baghizaden et al [28]
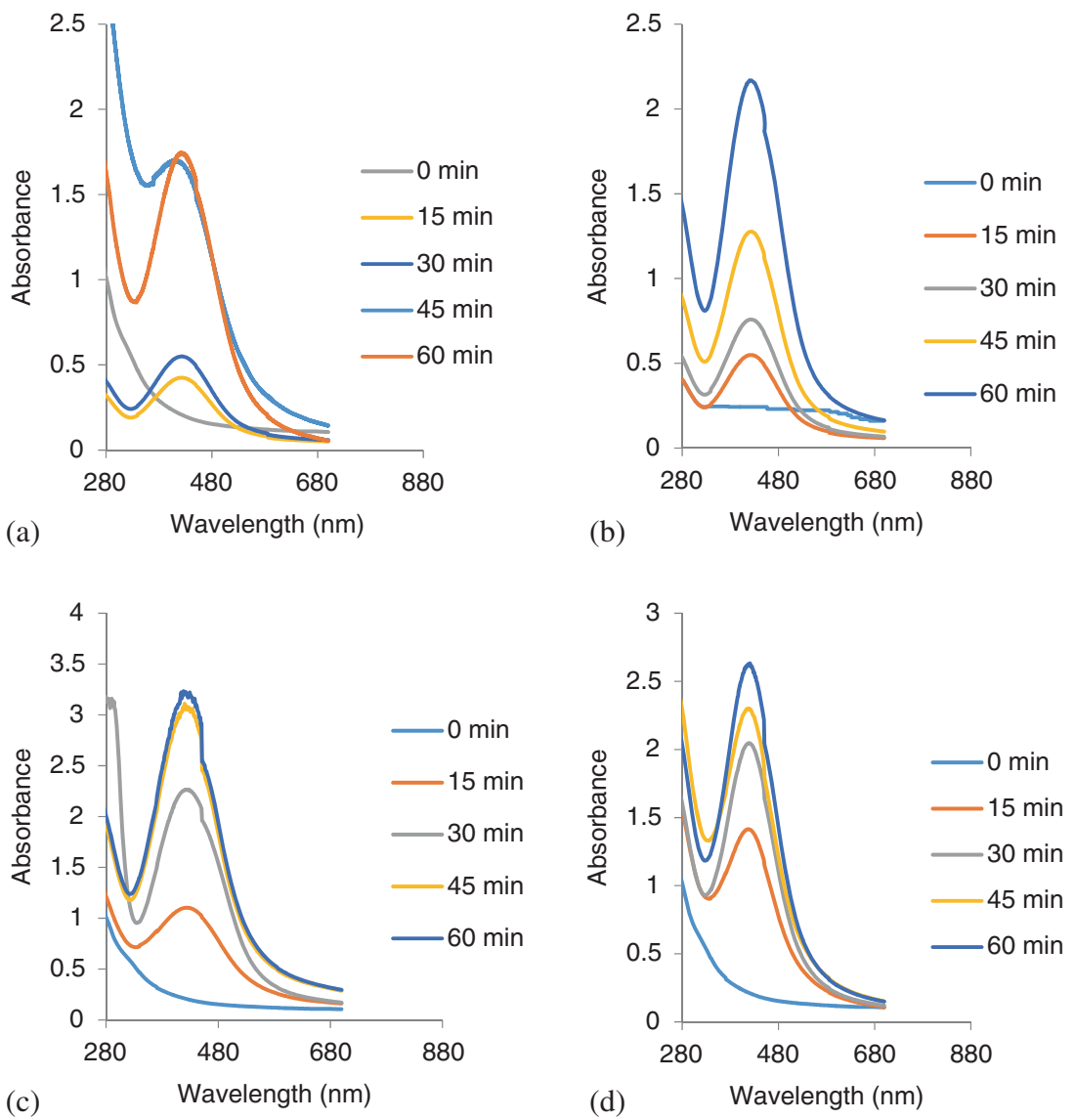

Figure 2. UV-vis absorption spectra of LA-mediated silver nanoparticles measured at ratio (1:10) at (a) 35 , (b) 45 , (c) 55 and (d) $65^{\circ} \mathrm{C}$ reaction temperature. 

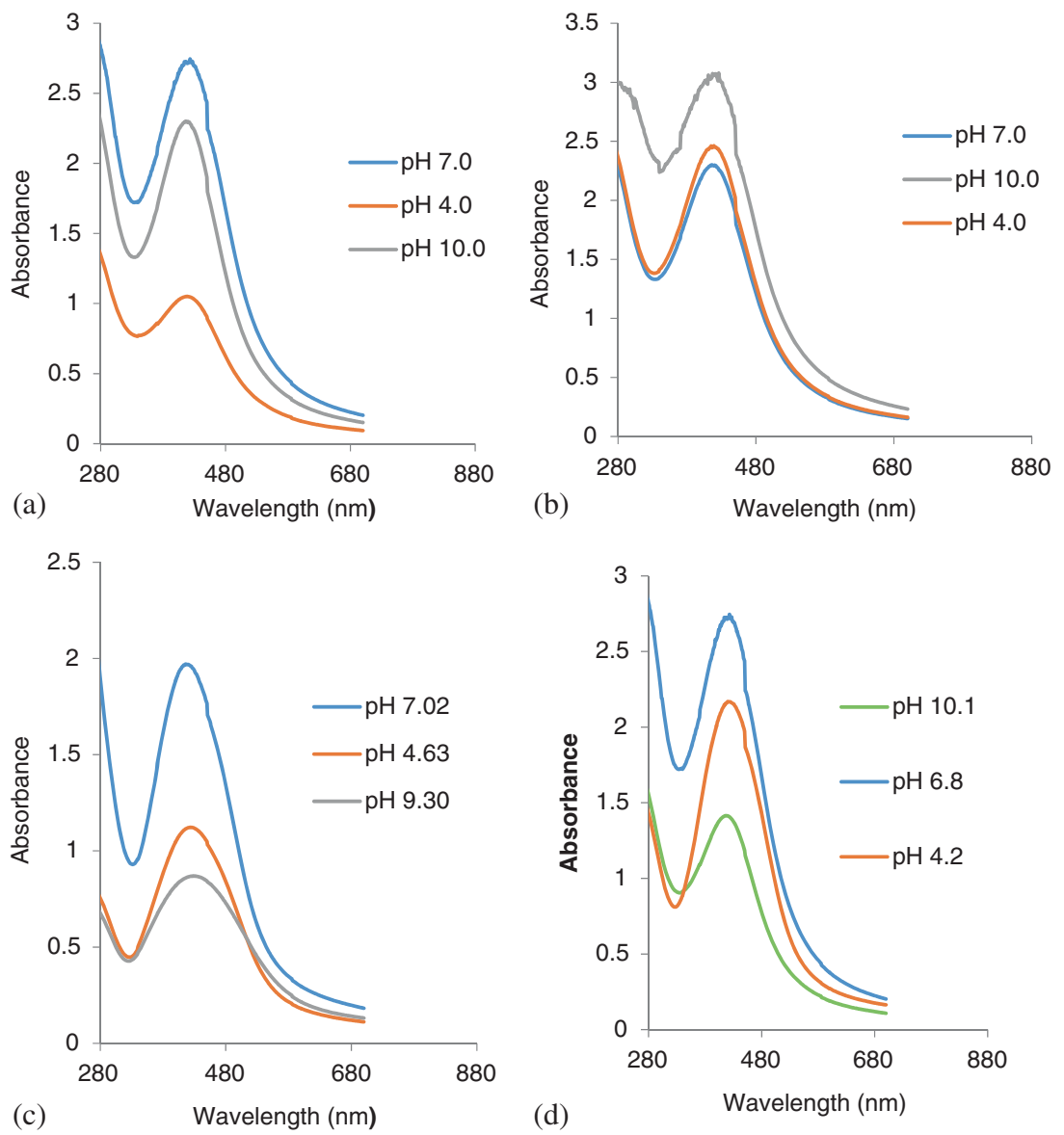

Figure 3. UV-vis absorption spectra of LA-mediated silver nanoparticles measured at $45^{\circ} \mathrm{C}$ at different $\mathrm{pH}(4,7,10):$ (a) 1:5, $45 \mathrm{~min}$; (b) 1:5, $60 \mathrm{~min}$; (c) 1:10, $45 \mathrm{~min}$ and (d) 1:10, $60 \mathrm{~min}$.

reported that the synthesis of AgNPs was completed in neutral condition, and there was no noticeable upheaval in UV-vis spectra with an increase in $\mathrm{pH}$. In a nutshell, the optimal $\mathrm{pH}$ for AgNPs synthesis is dependent on the substrate or stabilizing agent used. Based on our results, it could be inferred that neutral $\mathrm{pH}(6.8-7.0)$ is suitable for obtaining spherical small size nanoparticles using LA as a reducing and stabilizing agent at ratio $1: 10\left(1 \mathrm{mM} \mathrm{AgNO}_{3}\right)$, but at 1:5 ratio, alkaline medium is preferred. It is probable that increased concentration of the substrate also increased $\mathrm{OH}^{-}$concentration of some constituents of the extract, which thus changes the surface charge on the nanoparticles, thereby maximizing the repulsive electrostatic/electrosteric interactions and enhancing the stability [36,37]. More so, at higher $\mathrm{pH}$ values, Ag (I) ions in solution partly hydrolyse to form bioorganic- $\mathrm{Ag}(\mathrm{OH})_{x}$ complex on the surface of the particles and $\mathrm{AgOH} / \mathrm{Ag}_{2} \mathrm{O}$ colloid in the medium, which shows higher $k$-value than at the 1:10 ratio with preferred neutral medium as confirmed by the kinetics result in table 2 .

\subsection{Kinetics study}

The kinetics of the LA-mediated AgNPs was followed by UV-vis spectroscopy and modelled at different wavelengths of absorption maxima. There is a considerable increase in intensity of the SPB with contact time, suggesting that more nanoparticles are formed. Table 1 shows consistency of $k$-values at all reaction temperatures for 1:10 ratio of extract to $\mathrm{AgNO}_{3}$ both in pseudo-first- and -second-order kinetics. However, the values of $k$ are lower in the second order kinetics, signifying that it is the rate-controlling step. Although the reaction seems to follow either firstor second-order kinetics, pseudo-first order is the preferred reaction order due to the supported higher correlation coefficient $\left(R^{2}\right)$. The collapse in the surface plasmon bands becomes kinetically unfavoured and thermodynamically favoured. The absorbance at lower wavelength $(400 \mathrm{~nm})$ compared with the SNP (420 nm) shows that it is of higher energy. The slowest of these steps determines the rate of the processes, and from the kinetics plot's values presented in table 2, the pseudo-second order is the rate-controlling step for both 1:5 and 1:10 extract to $\mathrm{AgNO}_{3}$ ratios since they have lower rate constants.

The kinetics is an important concept in nanosynthesis due to the contributing factor of surface energy. Surface molecules experience weaker interactions than the interior ones, especially when they have reduced mobility. In order to maximize the interactions and enhance stronger cohesive 
Table 1. Absorbance values at different wavelengths of absorption maxima.

\begin{tabular}{|c|c|c|c|c|c|c|c|c|}
\hline \multirow[b]{2}{*}{$\begin{array}{l}\text { Time } \\
(\mathrm{min})\end{array}$} & \multicolumn{4}{|c|}{ Extract: $\mathrm{AgNO}_{3}$ ratio (1:5) } & \multicolumn{4}{|c|}{ Extract: $\mathrm{AgNO}_{3}$ ratio $(1: 10)$} \\
\hline & $\begin{array}{c}35^{\circ} \mathrm{C} \\
(412 \mathrm{~nm}) \\
\end{array}$ & $\begin{array}{c}45^{\circ} \mathrm{C} \\
(416 \mathrm{~nm})\end{array}$ & $\begin{array}{c}55^{\circ} \mathrm{C} \\
(423 \mathrm{~nm})\end{array}$ & $\begin{array}{c}65^{\circ} \mathrm{C} \\
(423 \mathrm{~nm}) \\
\end{array}$ & $\begin{array}{c}35^{\circ} \mathrm{C} \\
(410 \mathrm{~nm}) \\
\end{array}$ & $\begin{array}{c}45^{\circ} \mathrm{C} \\
(418 \mathrm{~nm}) \\
\end{array}$ & $\begin{array}{c}55^{\circ} \mathrm{C} \\
(429 \mathrm{~nm}) \\
\end{array}$ & $\begin{array}{c}65^{\circ} \mathrm{C} \\
(428 \mathrm{~nm}) \\
\end{array}$ \\
\hline 0 & 0.2528 & 0.2426 & 0.6019 & 0.2070 & 0.2267 & 0.2426 & 0.9858 & 0.2267 \\
\hline 15 & 0.4776 & 2.0443 & 1.0451 & 1.0466 & 0.4152 & 0.5476 & 1.1009 & 1.4010 \\
\hline 30 & 1.5420 & 2.6323 & 1.9367 & 2.2856 & 0.5367 & 0.7560 & 2.2602 & 2.0102 \\
\hline 45 & 1.5645 & 1.0493 & 1.9219 & 2.4431 & 1.6964 & 1.2728 & 3.0599 & 2.2740 \\
\hline 60 & 0.8221 & 1.4116 & 2.1883 & 2.7459 & 1.7024 & 2.1592 & 3.2215 & 2.5964 \\
\hline
\end{tabular}

Table 2. Rate constants, correlation coefficient and intercept obtained from pseudo-first- and -secondorder kinetics at different wavelengths of absorption maxima.

\begin{tabular}{|c|c|c|c|c|c|c|}
\hline \multirow[b]{2}{*}{ Temp } & \multicolumn{3}{|c|}{ Pseudo-first order, 1:5 (extract: $\mathrm{AgNO}_{3}$ ) } & \multicolumn{3}{|c|}{ Pseudo-second order, 1:5 (extract: $\mathrm{AgNO}_{3}$ ) } \\
\hline & $K_{1}$ & $R^{2}$ & Intercept & $K_{2}$ & $R^{2}$ & Intercept \\
\hline 35 & -0.0236 & 0.5119 & -0.9948 & -0.0462 & 0.6237 & 3.0975 \\
\hline 45 & -0.019 & 0.2337 & -0.439 & -0.0424 & 0.4076 & 2.603 \\
\hline 55 & -0.0145 & 0.8424 & -0.0068 & -0.0185 & 0.787 & 1.3643 \\
\hline \multirow[t]{2}{*}{65} & -0.0401 & 0.771 & -0.9632 & -0.0632 & 0.6011 & 3.2958 \\
\hline & \multicolumn{3}{|c|}{ Pseudo-first order, 1:10 (extract: $\mathrm{AgNO}_{3}$ ) } & \multicolumn{3}{|c|}{ Pseudo-second order, 1:10 (extract:AgNO 3 ) } \\
\hline Temp & $K_{1}$ & $R^{2}$ & Intercept & $K_{2}$ & $R^{2}$ & Intercept \\
\hline 35 & -0.0363 & 0.9294 & -1.4732 & -0.0631 & 0.8979 & 3.8657 \\
\hline 45 & -0.0348 & 0.9834 & -1.3004 & -0.0557 & 0.8327 & 3.3756 \\
\hline 55 & -0.044 & 0.8047 & -1.0028 & -0.0535 & 0.4135 & 3.4112 \\
\hline 65 & -0.0357 & 0.7115 & -0.8062 & -0.0555 & 0.5661 & 2.9548 \\
\hline
\end{tabular}

forces within a material, there must be minimization of surface-volume ratio by obtaining morphologies like spheres [38]. The intensities of the SPBs obtained in this research give idea about the mobility of the nanoparticles. The higher percentage of surface molecules encountered on a smaller domain at an elevated temperature seems to maximize the cohesive interactions within the nanoparticles, thereby driving the reaction towards minimized surface-volume ratio. Large interplanar spacings are associated with a low surface energy; hence the slow growth rate implies dense packings of the atoms. Bravais-Friedel-Donnay-Harker and HartmanPerdok predicted that the morphology of a crystal or particle is dominated by slow growing faces as the fast growing faces grow out and are therefore not represented in the morphology [39]. In other words, the morphology of the nanoparticles obtained in this reaction is a result of contribution of second-order kinetics.

Also from table 1, as the temperature increases, there is a shift to longer wavelength (red-shift) but the spectra become narrower, signifying monodispersed nature of the nanoparticles. Table 2 gives the rate constants and correlation coefficients obtained from first- and second-order rate plots, and from the values obtained, the best correlation coefficient $\left(R^{2}\right)$ value was obtained at $45^{\circ} \mathrm{C}$ using $1: 10$ extract to $\mathrm{AgNO}_{3}$ ratio.

\subsection{Thermodynamics of the surface reaction}

When metal nanoparticles form in the solution, they must be stabilized against the Van der Waals forces, which may cause coagulation. The stabilization may occur in a number of ways: physisorbed surfactant and polymers may create steric or electrosteric barriers or purely electrostatic barriers around the particle surface $[36,40]$. Such an action, which is brought about by the bio-organic capping agents, is responsible for the thermodynamics and stability of the nanoparticles.

The thermodynamics of the surface reaction could be followed using the equation below [41]:

$$
\ln \theta=A-\frac{B}{T}
$$

Nanoparticles are formed with time, and the intensity or absorbance as given by the UV-vis spectra is proportional to the concentration. Hence the mechanism of the nanoparticle formation is a surface adsorption phenomenon.

From equation ( 3 ), $\theta$ represents the surface particle (adsorbates), which could be taken as the absorbance at maximum wavelength. The above equation is similar to the ClausiusClapeyron equation, but it may not be easy to solve since there are two unknowns ( $A$ and $B$ ). As a result, an alternative 
Table 3. Absorbance at $428 \mathrm{~nm}$ at different temperatures and time of reaction for 1:10 ratio.

\begin{tabular}{|c|c|c|c|c|c|c|c|c|c|c|c|}
\hline \multicolumn{5}{|c|}{$\operatorname{Abs}(\theta)$} & \multicolumn{5}{|c|}{$\ln (\theta)$} & \multirow[b]{2}{*}{ Temp $(T / \mathrm{K})$} & \multirow[b]{2}{*}{$1 / T \times 10^{-3}(\mathrm{~K})$} \\
\hline $60 \mathrm{~min}$ & $45 \min$ & $30 \min$ & $15 \mathrm{~min}$ & $0 \mathrm{~min}$ & $60 \mathrm{~min}$ & $45 \mathrm{~min}$ & $30 \mathrm{~min}$ & $15 \mathrm{~min}$ & $0 \mathrm{~min}$ & & \\
\hline 1.734 & 1.66 & 0.55 & 0.42 & 0.20 & 0.55 & 0.51 & -0.60 & -0.86 & -1.60 & 308 & 3.25 \\
\hline 2.16 & 1.27 & 0.76 & 0.46 & 0.24 & 0.77 & 0.24 & -0.28 & -0.78 & -1.42 & 318 & 3.14 \\
\hline 3.19 & 3.03 & 2.26 & 1.10 & 0.20 & 1.16 & 1.11 & 0.82 & 0.10 & -1.62 & 328 & 3.05 \\
\hline 2.57 & 2.25 & 2.01 & 1.38 & 0.20 & 0.94 & 0.81 & 0.70 & 0.32 & -1.62 & 338 & 2.96 \\
\hline
\end{tabular}

Table 4. Calculated thermodynamic parameters.

\begin{tabular}{llccc}
\hline Time (min) & \multicolumn{1}{c}{$R^{2}$} & $\Delta H\left(\mathrm{JK}^{-1} \mathrm{~mol}^{-1}\right)$ & $\Delta S\left(\mathrm{JK}^{-1} \mathrm{~mol}^{-1}\right)$ & $\Delta G\left(\mathrm{JK}^{-1} \mathrm{~mol}^{-1}\right)$ \\
\hline 0 & 0.0793 & -1.85 & -0.0005 & $-1.691,-1.686,-1.681,-1.676$ \\
15 & 0.8771 & +37.89 & 0.112 & $3.394,2.274,1.154,0.034$ \\
30 & 0.836 & +43.26 & 0.128 & $3.836,2.556,1.276,0.00$ \\
45 & 0.3552 & +14.98 & 0.044 & $1.428,0.988,0.548,0.108$ \\
60 & 0.6285 & +13.73 & 0.041 & $1.108,0.692,0.282,-0.128$ \\
\hline
\end{tabular}

equation, the Gibbs-Helmholtz equation, may be introduced to solve the thermodynamic parameters:

$$
\begin{aligned}
& \ln \theta=-\frac{\Delta H}{R T}, \\
& \frac{d \ln \theta}{d T}=-\frac{\Delta H}{R T^{2}} .
\end{aligned}
$$

Further integration of the equation gives

$$
\ln \theta=-\frac{\Delta H}{R T}+\frac{\Delta H}{R T_{0}}+\ln \theta_{0} .
$$

A plot of $\ln \theta_{T}$ against $1 / T$ gives $-\frac{\Delta H}{R}$ as slope and $\ln \theta_{0}$ as intercept at the $y$-axis while $\frac{\Delta H}{R T_{0}}$ becomes the intercept at the $x$-axis.

Table 3 gives the values of absorbance at a wavelength of $428 \mathrm{~nm}$ at different temperatures and times of nanoparticle reaction.

The following linear equations were obtained from the plots of $\ln \theta$ vs. 1/T at different times of the reactions:

At 0 min, $y=0.2219 x-2.253$,

At 15 min, $y=-4.5569 x-13.821$,

At 30 min, $y=-5.2035 x+16.289$,

At 45 min, $y=-1.8019 x+6.2528$,

At $60 \mathrm{~min}, y=-1.6515 x+5.9747$.

To evaluate other thermodynamic parameters, Eqs. (7)-(10) are applied:

$$
\begin{aligned}
& \Delta H=\int_{T_{1}}^{T_{2}} c_{\mathrm{p}} d T=c_{\mathrm{p}}\left(T_{2}-T_{1}\right), \\
& \Delta S=c_{\mathrm{p}} \frac{\ln T_{2}}{T_{1}}+R \ln \frac{P_{1}}{P_{2}} .
\end{aligned}
$$

At constant pressure, $\Delta S=c_{\mathrm{p}} \ln \frac{T_{2}}{T_{1}}$.

$$
\Delta G=\Delta H-T \Delta S .
$$

The values of the calculated thermodynamic parameters are shown in table 4 , and the $\Delta G$ value indicated that the nanoparticle formation reaction was spontaneous at $338 \mathrm{~K}$ and above.

The results in table 4 show that at the onset of the nanosynthesis, the reaction tends to be exothermic, judging from the negative values of the enthalpy. However, as the reaction progressed it changed to endothermic nature, requiring energy to accomplish the process. The free energy values also show that at the beginning of the reaction, spontaneity was observed, but it tends to be non-spontaneous until at a higher temperature of $65^{\circ} \mathrm{C}$ and contact time of $60 \mathrm{~min}$. An equilibrium reaction was observed at $65^{\circ} \mathrm{C}$ after $30 \mathrm{~min}$ reaction time. The low and positive entropy values, which tend to increase up to $30 \mathrm{~min}$ and then decline, suggest that more energy is available for useful work at later reaction times. Molecules on the surface are energetically less stable and kinetically favoured than the ones in the interior, which are well-ordered. The entropy values showed that the molecules moved from an orderly sequence at the initial time of the reaction to disorderly nature, representing dissociation rather than association, which tends to be thermodynamically favoured at higher contact time judging from the fluctuation in the entropy values at 45 and 60 min contact time. At this time, crystal growth could be suggested to be setting into the process due to the OR mechanism, a phenomenon that explains the diffusion-controlled crystal growth process, in which larger particles grow at the expense of smaller particles [42]. The TEM image in figure 4 gives a particle range of $6.53-25.06 \mathrm{~nm}$, shows the smaller particles and also larger ones growing at the expense of the smaller particles.

\subsection{Morphology study}

Figure $4 \mathrm{a}$ and $\mathrm{b}$ contains representative TEM images of the LA-mediated $\mathrm{AgNPs}$ prepared at $65^{\circ} \mathrm{C}$ reaction temperature using (1:10) extract-precursor ratio, and for 15 and 

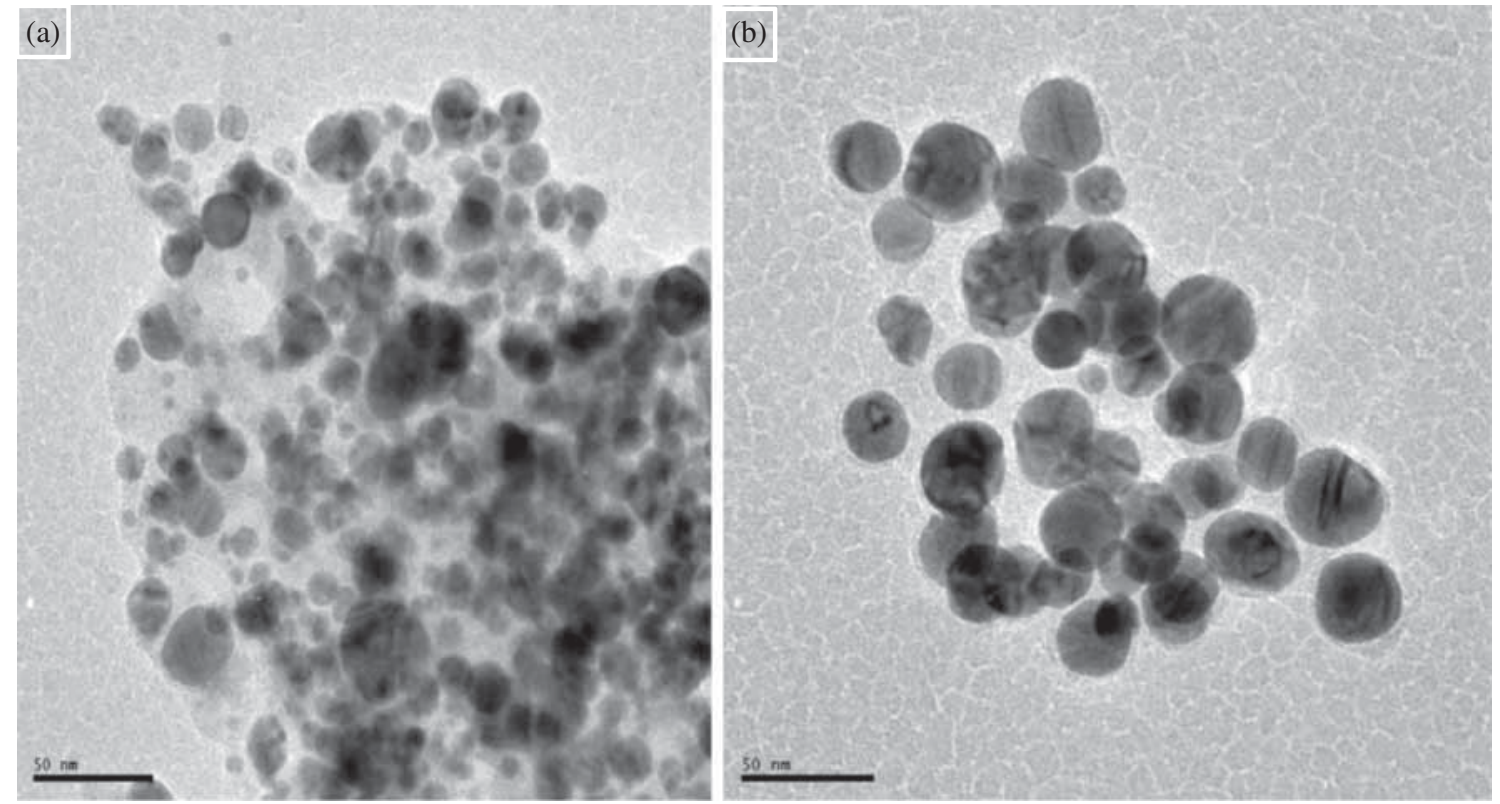

Figure 4. A representative TEM image of the silver nanoparticles prepared at $65^{\circ} \mathrm{C}$ reaction temperature using $(1: 10)$ extract-precursor ratio, and for (a) 15 and (b) 60 min reaction time.

60 min reaction times, respectively. The TEM images show the presence of spherically shaped AgNPs in accordance with the UV-vis spectral study. The TEM image reveals a wide variation in size of $8-35 \mathrm{~nm}$ at $15 \mathrm{~min}$ reaction time, and an average mean diameter of $38 \mathrm{~nm}$ after $60 \mathrm{~min}$ reaction time. These results confirm that the diameters of the AgNPs synthesized using this method also depend on the time of reaction. The AgNPs after $60 \mathrm{~min}$ formed bigger sized nanoparticles of closer size range than the particles obtained after $15 \mathrm{~min}$, hence indicating that the reaction time of the synthesis played a role in the process. It is possible that at the onset of the reaction, the molecules from the plant extract were not uniformly bound to the surface of the particles, therefore resulting in particles of varying sizes. However, at prolonged time of reaction and high temperature the alignment into bigger particles with uniform morphology gradually occurs, as evident in figure $4 \mathrm{~b}$. The organic molecules are well adsorbed on the surface of the nanosized particles, thus resulting in less aggregation.

\section{Conclusion}

A simple and biosynthesis method for colloidal AgNPs synthesized directly using a plant extract of LA is successfully achieved. AgNPs were synthesized at different temperatures, $\mathrm{pH}$, concentrations and reaction times. The diameters of the biosynthesized AgNPs depended on the temperature and concentration as well as time of reaction. Thus, with the increase of reaction time and at different temperatures, the size of AgNPs increased. This work demonstrates the use of a natural, non-toxic and low-cost biological reducing agent to produce AgNPs in aqueous solution, thereby avoiding the use of hazardous and toxic reagents. The kinetic studies showed that the reaction proceeded through a preferred pseudo-firstorder kinetics at 1:10 reactants ratio and fine-tuning the bioprocess parameters enhances the possibilities of desired nano-product tailor made for particular applications.

\section{References}

[1] Shah M, Fawcett D, Sharma S, Tripathy S K and Poinern G E J 2015 Materials 87278

[2] Singh P, Kim Y-J, Zhang D and Yang D-C 2016 Trends Biotechnol. doi: 10.1016/j.tibtech.2016.02.006 (in press)

[3] Javed I H, Sunil K, Athar A H and Zaheer K 2011 Adv. Mater. Lett. 2188

[4] Rucha D, Venu M, Sanjeev K G and Prafulla K J 2012 Nanosci. Nanotechnol. Lett. 430

[5] Somaye B, Hossein A, Hossein Z and Morteza S 2011 Digest J. Nanomater. Biostruct. 6709

[6] Udousoro I and Udiong D 2013 Int. J. Food Nutr. Safety 381

[7] Adegoke A A and Adebayo-tayo B C 2009 Afr. J. Biotechnol. 877

[8] Sofowora A 1993 Medicinal plants and traditional medicine in Africa (Ibadan, Nigeria: Spectrum Books) vol 2, p 96

[9] Okokon J E, Antia B S and Umoh E E 2009 Afr. J. Tradit. Complement. Altern. Med. 6150

[10] Akpan M M, Odeomena C S, Nwachukwu C N and Danladi B 2012 Asian J. Plant Sci. Res. 2335

[11] Udosen E O, Udok U E and Unuigbe O S 1999 J. Food Biochem. 23571

[12] Goodsell D S 2004 Bionanotechnology: lessons from nature (Hoboken, New York: Wiley-Liss)

[13] Amooaghaie R, Saeri M R and Azizi M 2015 Ecotoxicol. Environ. Safety 120400

[14] Kumar V and Kumar S 2008 J. Chem. Technol. Biotechnol. 84151 
[15] Sanchez-Mendieta V and Vilchis-Nestor A R 2012 Green synthesis of noble metal (Au, Ag, Pt) nanoparticles, assisted by plant-extracts, noble metals Yen-Hsun Su (ed.) doi: 10.5772/ 34335 (Croatia: InTech) Available from: http://www.intechopen. com/books/noble-metals/green-synthesis-of-noblemetal-au-ag-pt-nanoparticles-assisted-by-plant-extracts

[16] Song J Y and Kim B S 2008 Bioprocess. Biosyst. Eng. 3279

[17] Chandran S P, Chaudhary M, Pasricha R, Ahmad A and Sastry M 2006 Biotechnol. Prog. 22577

[18] Pandey R A, Chakrabarti T, Ketan B and Ranteke G 2013 J. Chem. 20131

[19] Vanaja M, Rajeshkumar S, Paulkumar K, Gnanajobitha G, Malarkodi C and Annadurai G 2013 Adv. Appl. Sci. Res. 450

[20] Daizy P 2011 Spectrochim. Acta A 78327

[21] Mahitha B, Raju B D P and Dillip G R 2011 Digest J. Nanomater. Biostruct. 6135

[22] Vanaja M, Paulkumar K, Gnanajobitha G, Rajeshkumar S, Malarkodi C and Annadurai G 2014 Int. J. Met. 20141

[23] Swarnalathan R, Christina R, Shuruti B and Peyas 2012 Int. J. Nanomater. Biostruct. 225

[24] Elemike E E, Oseghale C O, Chuku A, Mfon R, Labulo A H, Owoseni M, Adesuji E T and Dare E O 2014 Micron 571

[25] Dare E O, Makinde O W, Ogundele K T, Osinkolu G A, Fasasi Y A, Sonde I, Bamgbose J T, Maaza M, Sithole J, Ezema F and Adewoye O O 2012 Nanomaterials 20121

[26] El-Sayed M A 2001 Acc. Chem. Res. 34257

[27] Kvitek O, Siegel J, Hnatowicz V and Svorcik V 2013 J. Nanomater. 20131
[28] Baghizadeh A, Ranjabar S, Gupta V K, Asif M, Pourseyed S, Karimi M J and Mohammadinejad R 2015 J. Mol. Liq. 207159

[29] Agnihotri S and Mukherji S 2014 RSC Adv. 43974

[30] Taylor J W, Chinwoo P, James E E, Ilke A, William D R and Nigel D B 2014 Nano Lett. 14373

[31] Poinern G E J, Chapman P, Shan M and Fawcett D 2013 Nano Bull. 2130101

[32] Vilchis-Nestor A R, Sánchez-Mendieta V, Camacho-López M A, Gómez-Espinosa R M and Arenas-Alatorre J A 2008 Mater. Lett. 623103

[33] Kasthuri J, Veerapandian S and Rajendiran N 2009 Colloids Surf. B Biointerfaces $\mathbf{6 8} 55$

[34] Huang L, Zhai M L, Long D W, Peng J, Xu L, Wu G Z, Jiuqiang Q L and Genshuan S W 2008 J. Nanopart. Res. 10 1193

[35] Ramnani S P, Biswal J and Sabharwal S 2007 Radiat. Phys. Chem. 761290

[36] Tripathy A, Raichur A M, Chandrasekaran N, Prathna T C and Mukherjee A 2010 J. Nanopart. Res. 12237

[37] Sastry M, Mayyaa K S and Bandyopadhyay K 1997 Colloids Surf. A 127221

[38] Wang Y, He J, Liu C, Chong W H and Chen H 2015 Angew. Rev. 552022

[39] Greer H F 2014 Mater. Sci. Technol. 30611

[40] Mulvaney P 1996 Langmuir 12788

[41] Nwadiogbu J O, Okoye P A C, Ajiwe V I and Nnaji N J N 2014 J. Environ. Chem. Eng. 21699

[42] Zhang J, Huang F and Lin Z 2010 Nanoscale 218 